\title{
Investigations on the structural, mechanical and photoconductive studies of pure and lanthanum doped potassium pentaborate single crystals \\ B. Munirathnam ${ }^{1}$ and J. Madhavan ${ }^{2^{*}}$ \\ ${ }^{1}$ Department of Physics, Sir Theagaraja College, Chennai - 600 021, India. \\ ${ }^{2}$ Department of Physics, Loyola College, Chennai- 600034. \\ jmadhavang@yahoo.com
}

\begin{abstract}
Single crystals of pure and lanthanum doped potassium pentaborate (KB5) have been successfully grown by slow solvent evaporation technique. The grown crystals are confirmed by powder X-ray diffraction (PXRD). The mechanical strengths of the pure and doped crystals were found out using Vicker's micro hardness tests. The Second Harmonic Generation (SHG) of the crystals are confirmed by $\mathrm{Nd}$ :YAG pulsed laser employing Kurtz powder technique. The photoconductive studies reveal the negative photoconductive nature of the grown crystals. Keywords: Lanthanum, potassium pentaborate, crystal growth.

Introduction

In the recent past years, efforts have been made by many researchers to develop ultraviolet lasers for industrial and medical applications. The experiments conducted by Becker (1998) proved that inorganic borate crystals are superior to other commonly used Nonlinear optics (NLO) materials for UV applications. Potassium pentaborate has been identified as an important material for non linear optical applications especially in visible and ultraviolet region. KB5 crystallizes in an orthorhombic crystal system and belongs to the space group Aba2. In the present work, pure and lanthum doped Potassium pentaborate single crystals are grown in deionized water using slow solvent evaporation technique. The grown crystals are confirmed by PXRD and are characterized by mechanical and photoconductive studies. The NLO property is confirmed by Kurtz technique.

Experimental
\end{abstract}

Fig. 1. Powder X-ray Diffraction Analysis of pure KB5

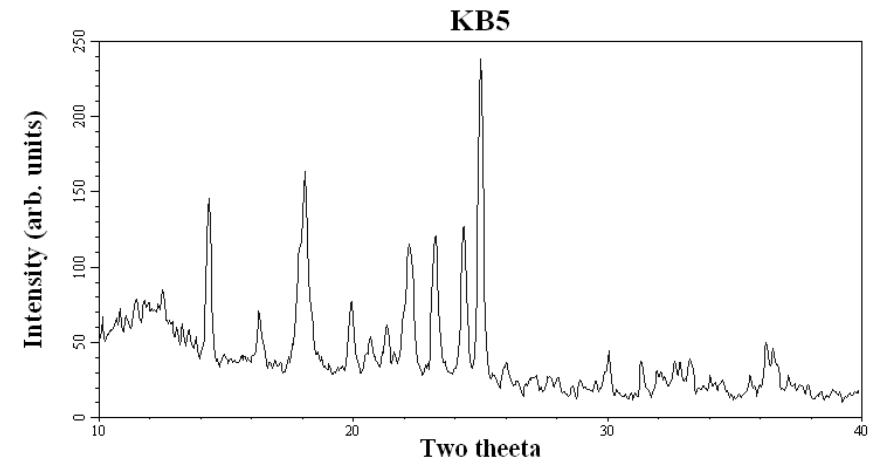

Single crystals of Potassium pentaborate with chemical formula $\mathrm{K}\left(\mathrm{H}_{4} \mathrm{~B}_{5} \quad \mathrm{O}_{10} \quad\right) .2 \mathrm{H}_{2} \mathrm{O}$ was synthesized by stoichiometric incorporation of potassium carbonate and boric acid taken in the appropriate ratio. The calculated amount of salt was dissolved in double distilled water. KB5 salt was synthesized according to the relation:

$\mathrm{K}_{2} \mathrm{CO}_{3}+10 \mathrm{H}_{3} \mathrm{BO}_{3} \rightarrow 2\left[\mathrm{~K}_{(}\left(\mathrm{H}_{4} \mathrm{~B}_{5} \mathrm{O}_{10}\right) \cdot 2 \mathrm{H}_{2} \mathrm{O}\right]+7 \mathrm{H}_{2} \mathrm{O}+\mathrm{CO}_{2} \uparrow$

Recrystallization was carried out more than three times to increase the purity of the crystal. The same process was repeated for the doped KB5 crystals. In doping process 0.05 mole of lanthum was added as dopant.

\section{Characterization}

Powder X-ray diffraction analysis

PXRD data of pure KB5 crystal indicates that it belongs to orthorhombic crystal system with space group Aba2. The data of the present work is in good agreement with the reported work (Becker et al., 2000). The XRD data of lanthum doped KB5 show that the crystal system remains unaltered. Fig. 1 \& 2 shows the PXRD pattern of pure and doped crystals. The lattice parameters of both pure and doped crystals are presented in Table 1.

Microhardness study

Microhardness behavior of the pure and doped crystals were tested by employing Vickers micro hardness test on the (001) plane. Measurements were taken by varying the applied load from 5 to $50 \mathrm{~g}$. Microcracks was developed at higher loads; therefore the maximum applied load was restricted to $50 \mathrm{~g}$ only. The plot of variation of Vickers hardness number $(\mathrm{Hv})$ with applied load for (001) plane of pure and doped KB5 is shown in Fig. 3. From the plot, it is noted that the hardness number $(\mathrm{Hv})$ of the crystal decreases with

Fig.2. Powder X-ray diffraction analysis of doped KB5

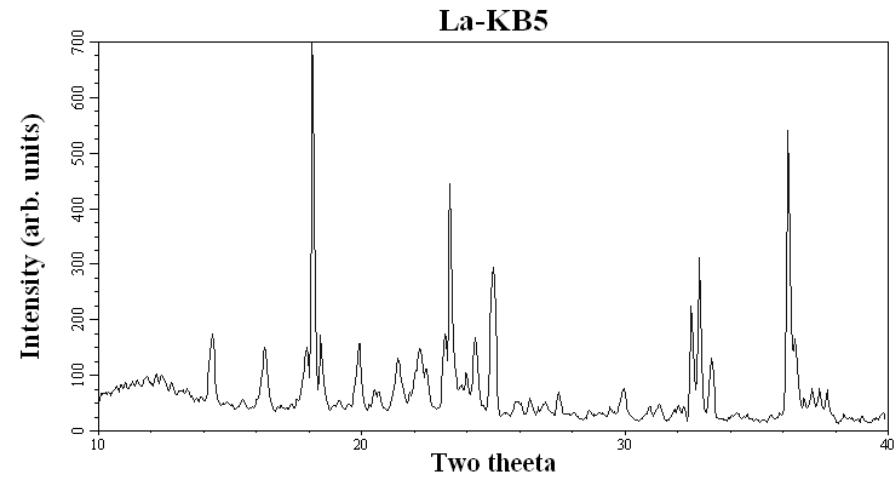

increasing load. This type of behavior wherein the hardness number decreases with increasing applied load is called normal indentation size effect (ISE)
Research article

CIndian Society for Education and Environment (iSee)
Munirathnam \& Madhavan Indian J.Sci.Technol. 
Indian Journal of Science and Technology

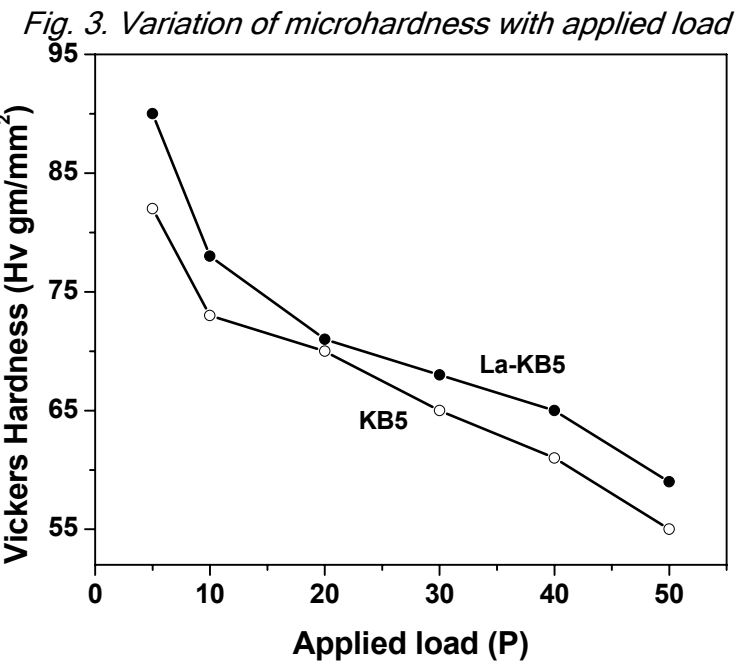

Table 1. Lattice parameters of pure and doped KB5 crystals

\begin{tabular}{|l|c|c|}
\hline Crystal system & Pure KB5 & $\mathrm{La}^{2+}$ doped KB5 \\
\cline { 2 - 3 } & Orthorhombic & Orthorhombic \\
\hline $\mathrm{a}(\AA)$ & 9.3 & 9.4 \\
\hline $\mathrm{b}(\AA)$ & 11.1 & 11.5 \\
\hline $\mathrm{c}(\AA)$ & 11.3 & 11.4 \\
\hline$\alpha(\mathrm{deg})$ & 90 & 90 \\
\hline$\beta(\mathrm{deg})$ & 90 & 90 \\
\hline $\mathrm{Y}(\mathrm{deg})$ & 90 & 90 \\
\hline Volume $\left(\AA^{3}\right)$ & 1166.5 & 1232.3 \\
\hline
\end{tabular}

(Mukerji \& Kar, 1999).

Photoconductivity study

Fig. 4 \& 5 shows the field dependence of dark and photo currents in pure and doped crystal respectively. The experiment was conducted on the (001) plane of the crystals. It is observed that both dark and photo currents increase linearly with the applied electric field with the photocurrent lesser than the dark current which is termed as negative photoconductivity (Joshi, 1990).

Fig. 5. Variation of current with applied field -La-KB5

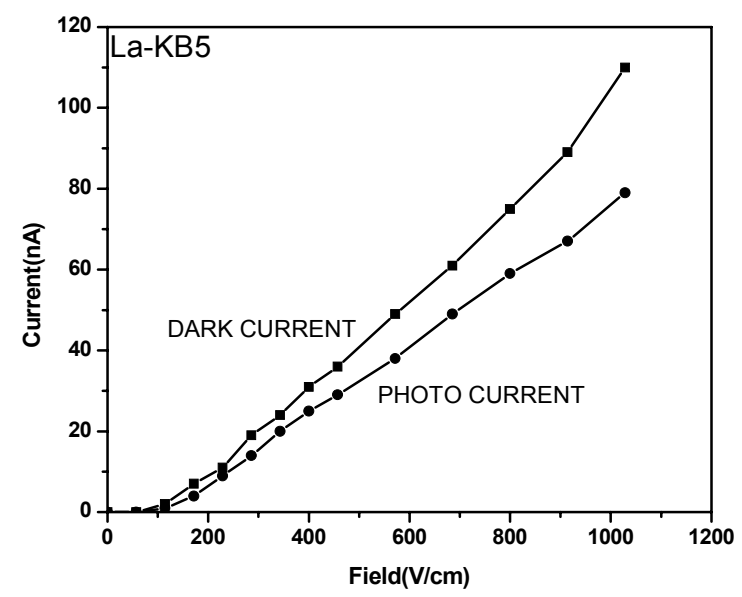

Vol.2 No 2 (Feb. 2009)

ISSN: $0974-6846$

Fig. 4. Variation of current with applied field - KB5

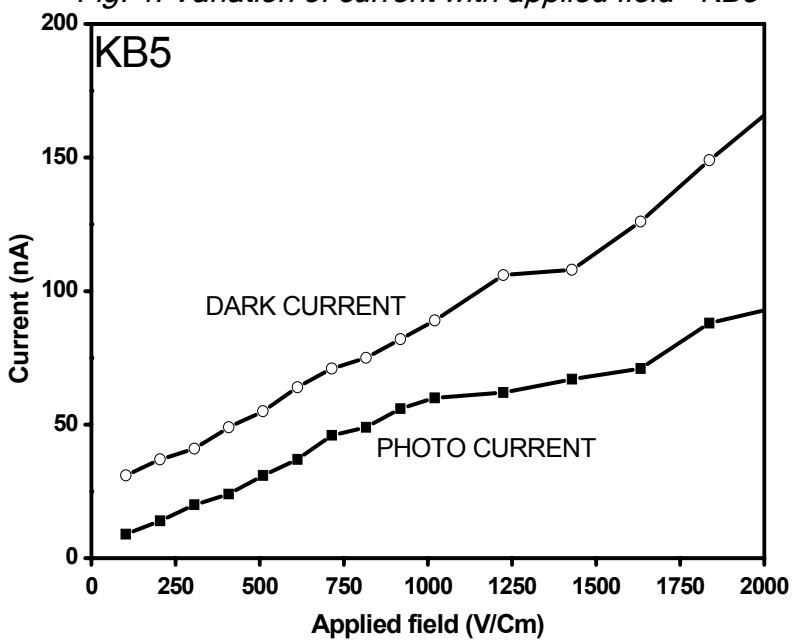

\section{Conclusion}

Pure and lanthum doped KB5 single crystals were grown by slow evaporation technique in room temperature. PXRD studies confirmed the structure of the grown crystals. The mechanical behavior is studied by Vickers hardness method. Photoconductive studies reveal the negative photoconducting nature of the grown crystals.

\section{References}

1. Becker $P$ (1998) Borate materials in nonlinear optics. Advanced Materials. 10, 979-992.

2. Becker P, Held P and Bohaty L (2000) Crystal growth and optical properties of the polar hydrated pentaborates $\mathrm{Rb}\left[\mathrm{B}_{5} \mathrm{O}_{6}(\mathrm{OH})_{4}\right] \cdot 2 \mathrm{H}_{2} \mathrm{O}$ and $\mathrm{NH}_{4}\left[\mathrm{~B}_{5} \mathrm{O}_{6}(\mathrm{OH})_{4}\right] \cdot 2 \mathrm{H}_{2} \mathrm{O}$ and structure redetermination of the ammonium compound. Cryst. Res. Technol. 35, 1251-1262.

3. Joshi VN (1990) Photoconductivity. Marcel Dekker, New York.

4. Mukerji S and Kar T (1999) Vicker's microhardness studies of L-arginine hydrobromide monohydrate crystals (LAHBr). Cryst. Res. Technol. 34, 13231328. 